\title{
Should Cannabis as Medicine be Specifically Regulated?
}

\author{
Gunawan Widjaja \\ Tarumanagara University, West Jakarta, Indonesia
}

\begin{abstract}
In 2017, a patient case in Sangau, West Kalimantan, involving a women with syringomyelia has drawn public attention. The case ended with the arrest of her husband who cultivated Cannabis to treat her disease. Currently, Indonesian regulation classifies Cannabis as the first group of narcotics which are prohibited to be used as medicine. This research aimed to ellaborate whether Cannabis as medicine should be specifically regulated. Data source was national and international regulation on narcotics and scientific evidence regarding medical benefit of Cannabis The data was obtained from literature search with following keywords; regulation of Cannabis, medical use of Cannabis, Cannabis medicine. Analysis was conducted using qualitative approach. The results of this study showed that Indonesian regulation regarding Cannabis is associated with International Convention on narcotics. Evidencebased data on Cannabis application in medical treatment have been extensively studied. Given beneficial effect of Cannabis to treat many diseases, several countries have already regulated the use of Cannabis for medical purpose. In conclusion, it is worth to consider a specific regulation for medical Cannabis in Indonesia, given its beneficial utilization to treat certain diseases.
\end{abstract}

Key words: Regulation, Cannabis, medical Cannabis, syringomelia

\section{Introduction}

In 2017, a patient case in Sangau, West Kalimantan, involving a women with syringomyelia drew public attention. Husband of the patient was arrested, trialed and sentenced for cultivation of Cannabis at his home grounds. Based on data from the case file No.111/Pid. Sus/2017/PN.Sag at Sangau Court of First Instance, it was clear that the cultivation of Cannabis by this man was only for the medical purpose, specifically to treat his wife. ${ }^{1}$

The wife had been in severe pain due to syringomelia for many years. Once every two weeks, she needed to be hospitalized. The patient was introduced with Cannabis treatment in 2016. After consuming cannabis, she felt better and could sleep without pain. She confessed that consumption of Cannabis never made her lost of consciousness. Eventually, she died not long after her husband was arrested and trialed. ${ }^{1,2}$

Current Indonesian regulation on Cannabis can be found in the Law No. 35/2009. All

Corresponding author: Gunawan Widjaja, Tarumanagara University, Bogor, West Java, Indonesia.

Email: widjaja_gunawan@yahoo.com

Received: 16 September 2018. Revised: 21 October 2018. Published: 19 December 2018. 
genus of Cannabis and all part of the plant, including the resin, tetrahydrocannabinol (THC), all its isomer, all its chemical stereoforms, delta-9 THC, and cannabidiol (CBD) are classified as narcotic group I. ${ }^{3}$ The aim of this study was to examine whether there was a need to formulate a specific regulation on the use of cannabis for medical purpose.

\section{Methods}

This is an explanatory research using qualitative approach. Data source was national and international regulation on narcotics and scientific evidence regarding medical benefit of cannabis. The data was obtained from literature search with following keywords; regulation of Cannabis, medical use of Cannabis, Cannabis medicine.

\section{Results and Discussion}

Legal aspect

Indonesian regulation on narcotics is associated with International Convention on Narcotics/1961. Indonesia was one of the 73 countries that become first member of the convention. Indonesian law regarding narcotics shall comply the international convention. Currently, legal statement regarding narcotics is provided in Law No. $35 / 2009$, which state that all genus of Cannabis and all part of the plants, including its derivatives are classified as narcotics group I. Article 8 paragraph (1) of Law No. $35 / 2009$ stated that narcotics listed in the group I are prohibited to be used for medical purpose. ${ }^{3}$

This law replaced Law No. 22/1997, and Law No. 9/1976. Nevertheless, under the Law No. 9/1976, Cannabis can be used for medical and scientific purposes. However, change was conducted in Law No. 22/1997, implying that narcotics listed in group I can only be used for scientific purpose. The use for other purposes are prohibited, including medical purpose. ${ }^{3,4}$

In 2015, the Ministry of Health issued a document No.LB.02.01/III.03/885/2015 regarding permission to use Cannabis in medical research as a response to a private research institute that intended to conduct a study on Cannabiss as potential drug candidate for type 2 diabetes mellitus. This document stated that this research should be performed by a team, involving researchers from that institute and Ministy of Health. Nevertheless, the research team from Ministry of Health still yet to be appointed, resulting in the delay of the research on medical application of Cannabis in Indonesia.

\section{Medical aspect}

Cannabinoids isolated from Cannabis plant has been extensively studied in medical research. The most frequent used cannabinoids are THC and CBD. Previous clinical trials suggested potential benefits of cannabinoids for alzheimer, dementia, Huntington disease, and other nervous system disorders. ${ }^{4,5}$ Other studies revealed that cannabinoids could reduce tumor growth in animal model of cancer by modulating signalling pathway in cell proliferation. ${ }^{6}$ Cannabinoids can also be used for palliative care, particularly in chemotherapy-induced nausea and vomiting due to its anti-emetic effect. ${ }^{7}$ In addition, CBD also exhibited anti-convulsant activity that can be used for epilepsy treatment. Compared to THC, CBD has better safety profile. ${ }^{7-11}$ Previous study also showed that cannabinoids exhibited modest effect in multiple sclerosis patients, particularly to treat spasticity. Further research are encouraged to compare the effectiveness of Cannabis compared to standard drugs. 
Regulation of medical Cannabis worldwide With development of scientific research related to medical use of Cannabis, there had been a changes in Cannabis regulation worldwide. In United States, although Controlled Substance Act (ACT), a legal statement that regulate drugs that has high potential for abuse, remained active, several states has regulated the possibility of using Cannabis for medical purpose. in 1996, California was the first state that legalize medical Cannabis.Previous study by Kilmer et al identified a 11 countries that legally allowed the use of cannabis for medical purpose, including Netherlands, Canada, Chile, United Kingdom, Czech Republic, Uruguay, Jamaica, Colombia, Australia and Germany. ${ }^{13}$ Australia enacted the law in 2016, while Germany did in 2017. THC and CBD were among the most frrequent used medical Cannabis. ${ }^{13-22}$

Our finding showed that there were enough evidence-based data that proved Cannabis can be used for medical purpose. There were also several on-going clinical trials related to the use of cannabis in medical therapy. For that reason, the regulations of medical cannabis should be considered. Document No. LB.02.01/III.03/885/2015 permitted a research using Cannabis in Indonesia. However, this study has never been performed. Many scientific researches can be perfomed with respect to the medical use of Cannabis in Indonesia. Pharmacoeconomic evaluation of the use of medicinal cannabis can also be performed to support the evidence on the clinical and economic benefit on the use of this product. It is worthwile to have a specific regulation on medical Cannabis, that would allow at least the registration of CBD and THC, which are benfeficial to improve for patient care.

\section{Conclusion}

It is worth to consider a specific regulation for cannabis to be used for medical purpose, given its beneficial application.

\section{Acknowledgements}

None.

\section{Funding}

None.

\section{Conflicts of Interest}

None declared.

\section{References}

1. Wirawan Jerome. Cannabis for Medicine: Proven or Archness. Available at:http://www.bbc.com/indonesia/ indonesia-39780294 [accessed 3rd July 2018].

2. Dania P, Blickman T. Cannabis in Indonesia: Consumption pattern, production and policy. Drug Policy Briefing. 2016;44:1-44.

3. Indonesian Law No. 35, 2009 regarding Narcotic. State Gazette Year 2009 No.143, Add. No.5062.

4. Indonesian Law No. 22, 1997. regarding Narcotic. State Gazette Year 1997 No.67, Add. No.3698

5. Rieder MJ. Is the medical use of cannabis a therapeutic option for children? Paediatric Child Health. 2016;21(1):314.

6. Aso E, Ferrer I. Cannabinoids for treatment of Alzheimer's disease: moving toward the clinic. Frontiers in Pharmacology. 2014;5:37.

7. Velasco G, Sánchez C, Guzmán M. Anticancer mechanisms of cannabinoids. Current Oncology. 2016;23(2):S23-32.

8. Perucca E. Cannabinoids in the treatment of epilepsy: Hard evidence at last? Journal of Epilepsy Research. 2017;7(2):61-76.

9. Nielsen S, Germanos R, Weier M, 
Pollard J, Degenhardt L, Hall W, et al. The use of cannabis and cannabinoids in treating symptoms of multiple sclerosis: A systematic review of reviews. Current Neurology and Neuroscience Repository. 2018;18:8.

10. Barry RA, Giantz S. A public health framework for legalized retail marijuana based on the US experience avoiding a new tobacco industry. PLOS Medicine. 2016;27:1-9.

11. Bergamaschi MM, Queiroz RH, Zuardi AW, Crippa JA. Safety and side effects of cannabidiol, a Cannabis sativa constituent. Current Drug Safety. 2011;6:237-249.

12. Bridgeman MB, Abazia DT. Medicinal cannabis: History, pharmacology, and implications for the acute care setting. Pharmacy and Therapeutics. 2017;42(3):180-188.

13. Volkow ND, Baler RD, Compton WM, Weiss SR. Adverse health effects of marijuana use. New England Journal Medicine. 2014;370(23):2219-27.

14. Rice J, Cameron M. Cannabinoids for treatment of multiple sclerosis symptoms: state of the evidence. Current Neurology and Neuroscience Report. 2018;18(8):50.

15. Kilmer B, Pacula RL. Understanding and learning from the diversification of cannabis supply laws. Addiction. 2016;112(7):1128-1135.

16. Hasin DS. US Epidemiology of Cannabis Use and Associated Problems. Neuropsychopharmacology. 2017;43(1):195-212.

17. Pacula RL, Kilmer B, Wagenaar AC, Chaloupka FJ, Caulkins JP. Developing public health regulations for marijuana: lessons from alcohol and tobacco. American Journal of Public Health. 2014;104(6):1021-8.

18. de Hoop B, Heerdink ER, Hazekamp A. Medicinal cannabis on prescription in the Netherlands: Statistics for 20032016. Cannabis Cannabinoid Research. 2018;3(1):54-55.

19. Lafaye G, Karila L, Blecha L, Benyamina A. Cannabis, cannabinoids, and health. Dialogues in Clinical Neuroscience. 2017;19(3):309-316.

20. Krcevski-Skvarc N, Wells C, Häuser W. Availability and approval of cannabisbased medicines for chronic pain management and palliative/supportive care in Europe. European Journal of Pain. 2018;22:440-54.

21. Abuhasira R, Shbiro L, Landschaft Y. Medical use of cannabis and cannabinoids containing product: regulations in Europe and North America. European Journal of Internal Medicine. 2018;49:2-6.

22. Degenhardt L, Ferrari AJ, Calabria B. The global epidemiology and contribution of cannabis use and dependence to the global burden of disease: results from the GBD 2010 study. PLoS One. 2013;8(10):e76635. 